\title{
Potential risk factors for the reactivation of the replication of hepatitis $B$ viruses after transcatheter arterial chemoembolization of hepatocellular carcinoma: a retrospective analysis
}

\section{Xiaoguang Wang ( $\square$ xiaoguangwangs@163.com )}

The second affiliated hospital of JiaXing university https://orcid.org/0000-0003-3865-7537

\section{Xiaodan Yang}

The Second Affiliated Hospital of Jiaxing University

Haitao Yu

The Second Affiliated Hospital of Jiaxing University

\section{Zhengwei Song}

The Second Affiliated Hospital of Jiaxing University

\section{Fei Chen}

The Second Affiliated Hospital of Jiaxing University

Jianguo Fei

The Second Affiliated Hospital of Jiaxing University

\section{Research}

Keywords: hepatocellular carcinoma, transcatheter arterial chemoembolization, hepatitis B virus, reactivation, immune function

Posted Date: April 6th, 2020

DOI: https://doi.org/10.21203/rs.3.rs-20985/v1

License: (9) This work is licensed under a Creative Commons Attribution 4.0 International License. Read Full License 


\section{Abstract}

Objective: To investigate the clinical features of hepatitis B virus(HBV) reactivation after transcatheter arterial chemoembolization (TACE) treatment in patients with hepatocellular carcinoma (HCC), and analyze the relationship between hepatitis $B$ virus reactivation and clinicopathological factors and prognosis.

Methods: Clinical data of 108 patients with HCC treated by TACE from January 2006 to January 2014 were retrospectively studied. The relationship between the clinical data and HBV reactivation were analyzed and the differences in survival rates between the reactivation group and the non-reactivation group were also compared.

Results: 42 (38.9\%) patients developed HBV reactivation. The reactivation rate in patients with HBV DNA $\geq 104$ was $65.8 \%$ (25/38), and was much higher than that of the patients with HBV DNA < 104 (24.3\%, 17/70). The cellular immune function of reactivation group was significantly lower than that of nonreactivation group $(P<0.01)$. There was a significant difference $(P=0.03)$ in 2-year survival rate between the activated and non-activated groups, and their survival rates were $35.9 \%$ and $53.3 \%$, respectively.

Conclusion: Some patients with primary hepatocellular carcinoma may have hepatitis B virus reactivation after receiving TACE treatment, and positive HBV DNA, immunosuppression were the risk factors for the development of HBV reactivation. Patients with hepatitis B virus reactivation after TACE have poor prognosis. The study suggests that antiviral therapy and immunoenhancer were necessary to improve curative effect and survival rate in HCC patients who underwent TACE.

\section{Introduction}

Hepatocellular carcinoma (HCC) is the sixth most common cancer and the third leading cause of cancerrelated death worldwide [1]. Cirrhosis, especially hepatitis B virus (HBV) or hepatitis C virus (HCV)-related cirrhosis, is widely considered to be the cause of HCC [2]. In China, HCC is always related to HBV-related cirrhosis. Because of high malignancy and obscure symptoms, most patients are diagnosed with HCC only at an advanced stage, when the radical resection rate is less than 30\% [3]. Transcatheter arterial chemoembolization (TACE) is an optimal therapy for unresectable and unablatable intermediate and advanced stage HCC [4-6]. The survival rate of HCC patients is better when they are treated with TACE [7, 8]. However, TACE may reactivate HBV, affecting liver function and prognosis of patients $[9,10]$. To investigate the factors affecting the reactivation of $\mathrm{HBV}$, an antiviral therapy must be appropriately provided to patients with HCC. Thus, we can protect the liver function and prolong the survival of patients with HCC.

In the present study, we retrospectively analyzed the clinical data of 108 HBV-related HCC patients, who had undergone TACE. Our aim is to analyze the factors affecting the reactivation of HBV by TACE and their relationship with prognosis of patients. Thus, we gathered sufficient information to develop an effective therapy for intermediate- and advanced-stage HCC patients. 


\section{Patients And Methods}

\section{Patients}

HBV-related HCC patients undergoing TACE from January 2006 to January 2014 at the Department of Hepatobiliary Surgery, Jiaxing Second Hospital were collected. The inclusion criteria were as follows: histological or clinical confirmation of HCC by early tumor staining and dynamic computed tomography (CT) or dynamic magnetic resonance imaging (MRI); age $\geq 20$ years; unresectable HCC; no indications for liver transplantation and local ablation therapy (radiofrequency ablation, percutaneous ethanol injection, and microwave coagulation); Child-Pugh A or B; Eastern Cooperative Oncology Group performance status (PS) 0-2; and life expectancy > 60 days. The exclusion criteria were as follows: any treatment for HCC was provided within 28 days before TACE; regular use of phenytoin, warfarin, or flucytosine; severe heart failure; uncontrollable diabetes mellitus; active infection; pregnancy or lactation; women of childbearing age, who did not used effective contraception; severe hypersensitivity to drugs; mental disorder; watery diarrhea; moderate or marked pleural effusion or ascites; and other serious medical conditions. All the patients followed the indications for TACE and received TACE therapy for the first time.

The research was approved by the Institutional Review Board of Jiaxing Second Hospital, Zheijiang, China. A written informed consent was obtained from each of the participants.

\section{Treatment}

TACE was performed using the Seldinger technique. Catheter was introduced into the common hepatic artery or proper hepatic artery by puncturing the common femoral artery in the right groin. Visceral angiography was carried out to assess the size, location, and arterial supply of the tumor. The tip of the catheter was introduced into the tumor-feeding artery. Then, floxuridine (500-1000 mg; Zhejiang HISUN Pharmaceutical, Zhejiang, China), epirubicin (60 mg; Pfizer, Bronx, NY, USA), cisplatin (60 mg; Qilu Pharmaceutical, Shandong, China), and iodized oil (10 mL; GUERBET, Villepinte, France) were injected into the tumor-feeding vessels. Thereafter, we performed embolization of tumor-feeding vessels by injecting particles of absorbable gelatin sponge (Jinling Pharmaceutical, Jianshu, China).

\section{Data collection, definition, and follow-up}

Data of all the selected patients were analyzed retrospectively. The HBV DNA levels and alpha-fetoprotein (AFP) levels were determined before the operation and one month after the operation. The numbers of CD3+, CD4+, and CD8+ T cells were measured using flow cytometry before the operation and one week after the operation. When HBV DNA levels > 1000 copies $/ \mathrm{mL}$, the patient was considered to be HBV DNA positive. HBV reactivation was defined as serum HBV DNA level was elevated 10 times more than the baseline level [11]. All the patients were followed up through outpatient service or telephone. 
The data were analyzed using SPSS (version 17; IBM, Chicago, IL, USA). The continuous variants were compared using $t$ test, while the portions were compared using chi square test. Survival analysis was performed using Kaplan-Meier analysis. Two-sided $P$-values of $<0.05$ were considered to be statistically significant.

\section{Results}

Characteristics of enrolled patients

A total of 108 patients were retrospectively analyzed in this study. There were 69 males and 39 females, with a mean age $58.69 \pm 10.23$ years (range 33-83 years). We classified 71 patients in Child-Pugh $A$ and 37 patients in Child-Pugh B. Furthermore, 81 patients had a single nodule, while 27 patients had multiple nodules. The mean size of nodules was $6.72 \pm 2.08 \mathrm{~cm}$ (range $3-11 \mathrm{~cm}$ ). There were 26 patients with the comorbidity of portal vein tumor thrombus (PVTT).

Changes of HBV DNA levels pre and post- TACE

Pre-TACE, 67.65\% (73/108) patients were tested positive for HBV DNA. One month after undergoing TACE, HBV was reactivated in 42 patients; 3 patients changed from HBV DNA negative to positive, while 39 patients showed a 10 fold increase in HBV DNA levels. Compared with the HBV DNA levels of 76 HBV DNA positive patients post-TACE, the HBV DNA levels were significantly higher in 73 HBV DNA positive patients at pre-TACE $\left(2.79 \pm 2.68 \times 10^{4}\right.$ copies $/ \mathrm{mL}$ vs $2.44 \pm 3.19 \times 10^{5}$ copies $\left./ \mathrm{mL}, P<0.01\right)$.

Changes of T cells pre- and post- TACE

As shown in Table 1, the numbers of CD3+ and CD4+ cells as well as the ratio of CD4+/CD 8+ were significantly decreased in patients post-TACE compared to that pre-TACE $(P<0.01)$. This indicates that the immune system was suppressed in patients after undergoing TACE.

Table 1. T cell changes in patients pre- and post- TACE

\begin{tabular}{lllll}
\hline T cell sub-groups & Pre-TACE & Post-TACE & $t$ value & $P$ value \\
\hline CD3+ (\%) & $55.36 \pm 8.76$ & $50.65 \pm 5.97$ & 4.718 & $<0.001$ \\
CD4+ (\%) & $26.79 \pm 4.31$ & $22.77 \pm 3.63$ & 7.335 & $<0.001$ \\
CD4+/CD8+ & $0.95 \pm 0.13$ & $0.83 \pm 0.17$ & 5.828 & $<0.001$ \\
\hline
\end{tabular}

Factors affecting $H B V$ reactivation 
We divided the patients into two groups, depending on whether HBV reactivation occurred or not. Then, we compared the clinical parameters of these two groups. As shown in Table 2, HBV reactivation was more likely to occur in patients with high HBV DNA level $\left(>10^{4}\right.$ copies $\left./ \mathrm{mL}\right)$ than in patients with low HBV DNA level $\left(<10^{4}\right.$ copies/mL $(65.79 \%$ [25/38] vs $24.29 \%$ [17/70], $P<0.01)$. Immune functions were significantly lower in patients with reactivated HBV $(P<0.01)$. In the two groups, no statistically significant difference was detected for the following parameters: age, gender, Hepatitis B e antigen (HBeAg) before and after TACE, child grade, comorbidity of liver cirrhosis, and comorbidity of PVTT.

Table 2. Characteristics and changes in patients with HBV reactivation and those without HBV reactivation 


\begin{tabular}{|c|c|c|c|c|}
\hline Characteristics & HBV reactivation $(n=42)$ & No reactivation $(n=66)$ & $t$ or $x^{2}$ & $P$ value \\
\hline Gender & & & 0.230 & 0.632 \\
\hline Male & 28 & 41 & & \\
\hline Female & 14 & 25 & & \\
\hline Age (years) & $57.40 \pm 9.59$ & $59.51 \pm 10.6$ & -1.046 & 0.298 \\
\hline Child-Pugh Grade & & & 2.256 & 0.133 \\
\hline$A$ & 24 & 47 & & \\
\hline B & 18 & 19 & & \\
\hline \multicolumn{5}{|l|}{$\mathrm{HBeAg}$} \\
\hline Positive & 25 & 29 & 0.606 & 0.436 \\
\hline Negative & 21 & 33 & & \\
\hline Liver cirrhosis & & & 2.651 & 0.104 \\
\hline Yes & 21 & 42 & & \\
\hline No & 22 & 23 & & \\
\hline HBV DNA pre-TACE (copies/mL) & & & 17.852 & $<0.001$ \\
\hline$\geq 10^{4}$ & 25 & 13 & & \\
\hline$<10^{4}$ & 17 & 53 & & \\
\hline Tumor diameter $(\mathrm{cm})$ & $6.83 \pm 2.12$ & $6.65 \pm 2.07$ & 0.441 & 0.660 \\
\hline PVTT & & & 0.074 & 0.786 \\
\hline Yes & 10 & 16 & & \\
\hline No & 34 & 48 & & \\
\hline AFP pre-TACE $(\mathrm{ng} / \mathrm{mL})$ & $463.78 \pm 251.57$ & $430.44 \pm 254.21$ & 0.667 & 0.506 \\
\hline AFP post-TACE (ng/mL) & $333.90 \pm 200.31$ & $244.89 \pm 174.47$ & 2.435 & 0.017 \\
\hline \multicolumn{5}{|l|}{$\mathrm{T}$ cells pre-TACE } \\
\hline CD3+ (\%) & $55.77 \pm 9.72$ & $55.10 \pm 8.17$ & 0.387 & 0.700 \\
\hline CD4+ (\%) & $26.82 \pm 4.63$ & $26.76 \pm 4.12$ & 0.068 & 0.946 \\
\hline CD4+/CD8+ & $0.94 \pm 0.11$ & $0.96 \pm 0.14$ & -0.905 & 0.367 \\
\hline \multicolumn{5}{|l|}{ T cells Post-TACE } \\
\hline CD3+ (\%) & $48.57 \pm 6.28$ & $51.97 \pm 5.40$ & -2.992 & 0.003 \\
\hline CD4+ (\%) & $20.91 \pm 3.33$ & $23.95 \pm 3.30$ & -4.638 & $<0.001$ \\
\hline
\end{tabular}


HbeAg, hepatitis B e antigen; TACE, transcatheter arterial chemoembolization; PVTT, portal vein tumor thrombus; AFP, alpha fetoprotein.

\section{Survival}

All the patients were followed up through outpatient service or telephone. The median follow-up time was 17.8 months (range: 3-40 months). Nine (8.3\%) patients were lost to follow up. No significant difference was detected in the one year survival rate of HBV reactivation patients and no HBV reactivation patients $(69.2 \%$ vs $80.0 \%, P>0.05$; Figure $1 \mathrm{~A})$. However, the two year survival rate was significantly lower in HBV reactivation patients than that in no HBV reactivation patients ( $35.9 \%$ vs $53.3 \%, P=0.03$; Figure 1 B).

\section{Discussion}

\section{Retrospective ethics approval}

The samples included 108 patients with HCCwho had treated by TACE between 2006 and 2014. All patients signed the informed consent form. The research was approved by the Ethics Committee of The Second Affiliated Hospital of Jiaxing University.

\section{Consent for publication}

All individual person's data and case reports have been approved for publication.

\section{Availability of data and materials}

The datasets used during the current study are available from the corresponding author on reasonable request.

\section{Funding information}

This work was supported by the science and technology planning project of Jiaxing City(No.2017AY33037).

\section{Authors' contributions}

Xiaoguang Wang have made substantial contributions to the conception; Jianguo Fei have made substantial contributions to the design of the work; Xiaodan Yang, Haitao Yu, Zhengwei Song, Fei Chen have made substantial contributions to the acquisition, analysis and interpretation of data.Each author approved the submitted version, agreed both to be personally accountable for the author's own contributions and to ensure that questions related to the accuracy or integrity of any part of the work. 
Acknowledgements

Thank you for the writing assistance provided by Pengfei YU.

\section{Conflict of Interest}

The authors declare that they have no competing interests.

\section{References}

[1]Bosch FX, Ribes J, Cléries R, Díaz M. Epidemiology of hepatocellular carcinoma. Clin Liver Dis 2005; 9 : 191-211.

[2]Zhang J, Shao CX. Research progress for early diagnosis of hepatocellular carcinoma. Chin J Hepatobiliary Surg 2014; 20: 689-93.

[3] Hu L, Xue F, Li Y, Shao M, Sun Y, Wei G. A long-term follow-up and comprehensive observation of risk and prognosis factors of recurrence and survival after resection of hepatocellular carcinoma. Cell Biochem Biophys 2014; 69: 421-31.

[4]Xiao J, Li G, Lin S, He K, Lai H, Mo X, Chen J, et al. Prognostic factors of hepatocellular carcinoma patients treated by transarterial chemoembolization. Int J Clin Exp Pathol 2014; 7: 1114-23.

[5]Lao XM, Luo GY, Ye LT, Luo C, Shi M, Wang D,et al. Effects of antiviral therapy on hepatitis B virus reactivation and liver function after resection or chemoembolization for hepatocellular carcinoma. Liver Int 2013; 33: 595-604.

[6] Kariyama K, Nouso K, Wakuta A, Oonishi A, Toyoda H, Tada T,et al. Treatment of Intermediate-Stage Hepatocellular Carcinoma in Japan: Position of Curative Therapies. Liver Cancer. 2020;9(1):41-49.

[7]Tian X, Dai Y, Wang DQ, Zhang L, Sui CG, Meng FD,et al. Transarterial chemoembolization versus hepatic resection in hepatocellular carcinoma treatment: a meta-analysis. Drug Des Devel Ther 2015; 9 : 4431-40.

[8]Feng AL, Zhu JK, Yang Y, Wang YD, Liu FY, Zhu M,et al. Repeated postoperative adjuvant TACE after curative hepatectomy improves outcomes of patients with HCC. Minim Invasive Ther Allied Technol. 2019; 27:1-6.

[9]Vizzini GB, Luca A, Marino IR. Hepatitis B virus reactivation after a single session of transarterial chemoembolization in patients with hepatocellular carcinoma. Ann Intern Med 2003; 138: 691-2.

[10]Lao XM, Wang D, Shi M, Liu G, Li S, Guo R,et al. Changes in hepatitis B virus DNA levels and liver function after transcatheter arterial chemoembolization of hepatocellular carcinoma. Hepatol Res 2011; 41: 553-63. 
[11] Lao CA, Lee CM, Wu HC, Wang MC, Lu SN, Eng HL. Lamivudine for the treatment of hepatitis B virus reactivation following chemotherapy for non-Hodgkin's lymphoma. Br J Haematol 2002; 116: 166-9凶

[12]Peng Z, Cao G, Hou Q, Li L, Ying S, Sun J,et al. The comprehensive analysis of efficacy and safety of CalliSpheres ${ }^{\circledR}$ drug-eluting beads transarterial chemoembolization in 367 liver cancer patients: a multiplecenter, cohort study. Oncol Res. 2019

[13] Ashtari S, Pourhoseingholi MA, Sharifian A, Zali MR. Hepatocellular carcinoma in Asia: Prevention strategy and planning. World J Hepatol 2015; 7: 1708-17.

[14]Rossi G. Prophylaxis with lamivudine of hepatitis B virus reactivation in chronic HbsAg carriers with hemoto-oncological neoplasias treated with chemotherapy. Leuk Lymphoma 2003; 44: 759-66】

[15] Pei SN, Chen $\mathrm{CH}$. Risk and prophylaxis strategy of hepatitis B virus reactivation in patients with lymphoma undergoing chemotherapy with or without rituximab. Leuk Lymphoma 2015; 56: 1611-8.

[16] Jang JW, Choi JY, Bae SH, Kim CW, Yoon SK, Cho SH,et al. Transarterial chemolipiodolization can reactivate hepatitis $B$ virus repication in patients with hepatocellular carcinoma. Hepatology 2004; 41 : 427-45.

[17] Dai M, Chen X, Liu X, Peng Z, Meng J, Dai S. Diagnostic Value of the Combination of Golgi Protein 73 and Alpha-Fetoprotein in Hepatocellular Carcinoma: A Meta-Analysis. PLoS One 2015; 10: e0140067.

[18] Ma WJ, Wang HY, Teng LS. Correlation analysis of preoperative serum alpha-fetoprotein (AFP) level and prognosis of hepatocellular carcinoma (HCC) after hepatectomy. World J Surg Oncol 2013; 11: 212-8.

[19] Wei Y, Yi Y, Tao C, Ye W, Zhao W. Impact of antiviral therapy with nucleos(t)ide analog on survival of patients with HBV-related small hepatocellular carcinomas. Cancer Manag Res. 2019;11:8475-86.

[20] Nagamatsu H, Itano S, Nagaoka S, Akiyoshi J, Matsugaki S, Kurogi J,et al. Prophylactic lamivudine administration prevents exacerbation of liver damage in HBe antigen positive patients with hepatocellular carcinoma undergoing transhepatic arterial infusion chemotherapy. Am J Gastroenterol 2004; 99: 236975区

[21]Jang JW, Choi JY, Bae SH, Yoon SK, Chang UI, Kim CW,et al. A randomized controlled study of preemptive lamivudine in patients receiving transarterial chemo-lipiodolization. Hepatology 2006; 43: 233-40.

[22]Jang JW. Hepatitis B virus reactivation in patients with hepatocellular Carcinoma undergoing anticancer therapy. World J Gastroenterol 2014; 20: 7675-85.

[23] Kim HY, Kim W. Chemotherapy-related reactivation of hepatitis B infection: updates in 2013. World J Gastroenterol 2014; 20: 14581-8. 
[24] Tan YW, Ye Y, Ge GH, Zhao W, Gan JH, Zhao Y,et al. Natural YMDD-motif mutants affect clinical course of lamivudine in chronic hepatitis B. World J Gastroenterol 2015; 21: 2089-95.

[25] Liaw YF, Kao JH, Piratvisuth T, Chan HL, Chien RN, Liu CJ,et al. Asian-Pacific consensus statement on the management of chronic hepatitis B: a 2012 update. Int J Hepatol 2012; 6: 531-61.

\section{Figures}


A

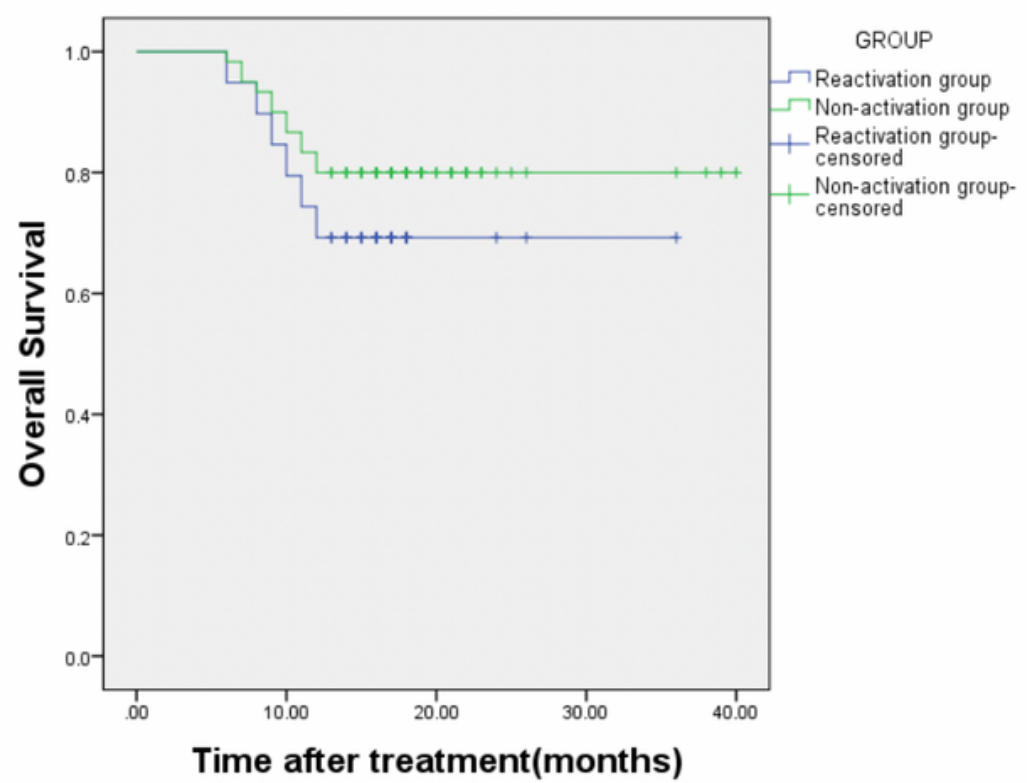

B

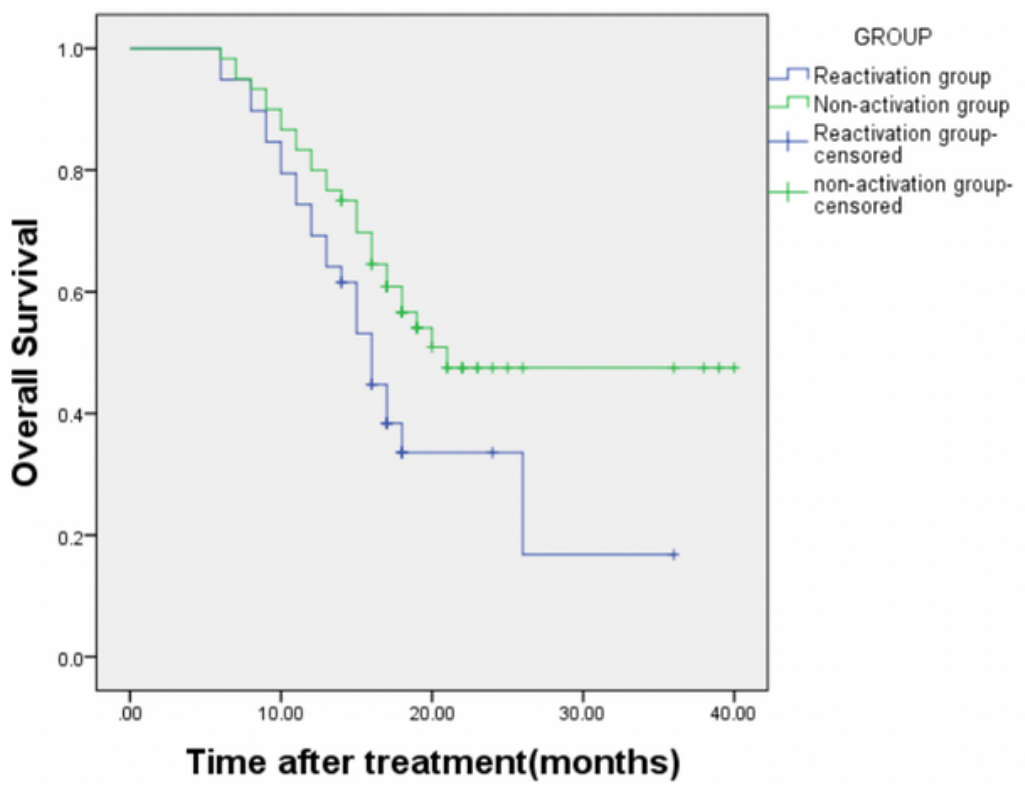

Figure 2

Survival curve of patients with HBV reactivation and those without HBV reactivation. A. One year; B. Two year. 